Article

\title{
Amplification Refractory Mutation System (ARMS)-PCR for Waxy Sorghum Authentication with Single-Nucleotide Resolution
}

\author{
Xiaoying Zhu ${ }^{1}$, Minghua $W_{u}{ }^{1}$, Ruijie Deng ${ }^{1, *}{ }^{1}$, Mohammad Rizwan Khan ${ }^{2} \mathbb{D}$, Sha Deng ${ }^{1}$, Xi Wang ${ }^{3, *}$, \\ Rosa Busquets ${ }^{4}\left(\mathbb{D}\right.$, Wanyu Deng ${ }^{1}$ and Aimin Luo ${ }^{1, *}$ \\ 1 Healthy Food Evaluation Research Center and Key Laboratory of Food Science and Technology of Ministry of \\ Education of Sichuan Province, College of Biomass Science and Engineering, Sichuan University, \\ Chengdu 610065, China; zhuxiaoying0627@163.com (X.Z.); wuminghua06@163.com (M.W.); \\ ds585455@foxmail.com (S.D.); wanyudeng@163.com (W.D.) \\ 2 Department of Chemistry, College of Science, King Saud University, Riyadh 11451, Saudi Arabia; \\ mrkhan@KSU.EDU.SA \\ 3 Sichuan Langjiu Group Co., Ltd., Luzhou 646523, China \\ 4 School of Life Sciences, Pharmacy and Chemistry, Kingston University London, Penrhyn Road, Kingston \\ upon Thames KT1 2EE, UK; r.busquets@kingston.ac.uk \\ * Correspondence: drj17@scu.edu.cn (R.D.); wangxi15283088230@163.com (X.W.); luoam@scu.edu.cn (A.L.)
}

check for updates

Citation: Zhu, X.; Wu, M.; Deng, R.; Rizwan Khan, M.; Deng, S.; Wang, X.; Busquets, R.; Deng, W.; Luo, A. Amplification Refractory Mutation System (ARMS)-PCR for Waxy Sorghum Authentication with Single-Nucleotide Resolution. Foods 2021, 10, 2218. https://doi.org/ $10.3390 /$ foods 10092218

Academic Editor: Bianca Castiglioni

Received: 8 August 2021

Accepted: 9 September 2021

Published: 18 September 2021

Publisher's Note: MDPI stays neutral with regard to jurisdictional claims in published maps and institutional affiliations.

Copyright: (c) 2021 by the authors. Licensee MDPI, Basel, Switzerland. This article is an open access article distributed under the terms and conditions of the Creative Commons Attribution (CC BY) license (https:// creativecommons.org/licenses/by/ $4.0 /)$.

\begin{abstract}
Waxy sorghum has greater economic value than wild sorghum in relation to their use in food processing and the brewing industry. Thus, the authentication of the waxy sorghum species is an important issue. Herein, a rapid and sensitive Authentication Amplification Refractory Mutation System-PCR (aARMS-PCR) method was employed to identify sorghum species via its ability to resolve single-nucleotide in genes. As a proof of concept, we chose a species of waxy sorghum containing the $\mathrm{wx}^{\mathrm{C}}$ mutation which is abundantly used in liquor brewing. The aARMS-PCR can distinguish non- $w x^{C}$ sorghum from $w x^{c}$ sorghum to guarantee identification of specific waxy sorghum species. It allowed to detect as low as $1 \%$ non- $\mathrm{wx}^{\mathrm{C}}$ sorghum in sorghum mixtures, which ar one of the most sensitive tools for food authentication. Due to its ability for resolving genes with singlenucleotide resolution and high sensitivity, aARMS-PCR may have wider applicability in monitoring food adulteration, offering a rapid food authenticity verification in the control of adulteration.
\end{abstract}

Keywords: ARMS-PCR; DNA barcode; food authenticity; sorghum; liquor

\section{Introduction}

Sorghum is the fifth largest cereal crop in the world. It is the main food crop in Africa and the raw material for many famous liquor companies in Southwest China. Waxy sorghum is more suitable for liquor brewing, compared with wild sorghum. For instance, high-quality liquor enterprises such as Kweichow moutai, Lang Jiu and Wuliangye all rely on waxy sorghum. The choice of sorghum species is based on the fact that waxy sorghum improved the digestibility of starch and protein, in contrast to wild sorghum [1,2]. It was reported that waxy sorghum led to higher ethanol yield and higher conversion efficiency than wild sorghum [3,4]. And, its waxy starch had lower gelatinization temperature, which reduced the energy demand in the ethanol production process and shortened the fermentation time [5,6]. In addition, waxy sorghum is also widely used in the food processing industry [7,8]. Mezgebe et al. found that the waxy sorghum powder had considerable potential in the production of gluten-free fermented flat cake products, it had good structure and function [9]. The Elhassan group found that waxy sorghum flour, with high protein digestibility, had better dough-like properties than non-waxy sorghum, with normal protein digestibility [10,11]. 
The market price of wild sorghum is usually half that of waxy sorghum, and the waxy sorghum varieties may also lead to differences in flavor of the liquors and the quality of foods where they are used. As a consequence, these differences between various species open the door for food adulteration by substituting high-value species with low-priced ones, as large profit margins can be achieved [12,13]. A vast majority of waxy sorghum are $w x^{\mathrm{a}}$ or $w x^{\mathrm{c}}$ in Southwest China, and many famous liquor enterprises usually use $w x^{\mathrm{c}}$ as the main raw material for brewing high-quality liquor. So it is necessary to assess its authenticity to guarantee the integrity and quality of the species used [14].

Waxy sorghum is the recessive mutant of wild sorghum. At present, four kinds of waxy sorghum have been found, named as $w x^{a}, w x^{b}, w x^{c}$, and $w x^{d}[15,16]$. Studies by Sattler showed that the $w x^{a}$ allele had a large insertion $(>4 \mathrm{~kb})$ in the third exon of the SbGBSS. The $w x^{b}$ allele had a missense mutation (+1G-to-T) in the eighth exon that changed glutamine 268 to a histidine. Yuangen $\mathrm{Lu}$ et al. identified another two waxy alleles, $\mathrm{wx}^{\mathrm{c}}$ and $w x^{d}$. The $w x^{c}$ allele had a $G$ deletion at the $5^{\prime}$ splicing site of the ninth intron, and the $w x^{d}$ allele had a G to $C$ mutation at the $3^{\prime}$ splicing site of the tenth intron. These single-nucleotide variants can be used as molecular markers to identify different sorghum species genetically.

In general, through physical-chemical methods, only wild sorghum and waxy sorghum can be distinguished separately. Therefore, the identification of waxy sorghum with different genotypes needs to be explored at the molecular level. At present, there are a few studies on the identification of different waxy sorghum. The current methods of choice for gene identification of waxy sorghum are Sanger sequencing and PCR $[17,18]$. The Sanger sequencing technique is considered to be very reliable and accurate, but has some drawbacks. For example, samples need to be sent to a certified testing agency, and it is time-consuming, usually taking $24 \mathrm{~h}$ to several days to finish the test. Some work used PCR to identify different waxy sorghum $[19,20]$. Usually, they cannot resolve a single nucleotide in gene sequences which often occur in different species of sorghum. Therefore, alternative methods are needed which allow an inexpensive and fast screening of relevant species with single-nucleotide resolution.

Amplification Refractory Mutation System (ARMS), known as allele-specific amplification, combined with PCR (ARMS-PCR), allows to identify gene barcodes with singlenucleotide resolution, and is widely used in clinic diagnosis for cancers [21]. However, its potential for food authentication has not been explored so far in a rapidly evolving food control scenario.

Herein, we introduce ARMS-PCR to identify sorghum species, and create a tool, termed authentication ARMS-PCR (aARMS-PCR), to identify sorghum species with singlenucleotide resolution. We chose a species of waxy sorghum containing $\mathrm{wx}^{\mathrm{C}}$ mutation which is abundantly used in liquor brewing. The aARMS-PCR can distinguish non- $w x^{c}$ sorghum from $\mathrm{wx}^{\mathrm{c}}$ sorghum to guarantee the identification of specific waxy sorghum species. It allowed to detect as low as $1 \%$ non- $w x^{\mathrm{c}}$ sorghum in sorghum mixtures, which are one of the most sensitive tools for food authentication. The aARMS-PCR would find wide applicability in food adulteration considering its ability to resolve genes with singlenucleotide resolution and high sensitivity $[22,23]$.

\section{Materials and Methods}

\subsection{Materials and Reagents}

'Hongyingzi' was provided from the Sichuan Langjiu Group Co., Ltd. (Luzhou, China), and 'Jinnuoliang No.6' and 'Jin 204' were obtained from Sichuan Academy of Agricultural Sciences (Chengdu, China). Ezup Food Genomic DNA Extraction Kit (cat. No. GA15KA7284), SanTaq Plus PCR Master Mix (cat. No. B532071) and 50×TAE buffer (cat. No. B548101) were all bought from Sangon (Shanghai, China). The $2 \times$ PerfectStartTM Green qPCR SuperMix (cat. No. B639275) and nuclease-free $\mathrm{H}_{2} \mathrm{O}$ were bought from Tiangen (Beijing, China). DNA primers were synthesized by Sangon (Shanghai, China), and were purified using Polyacrylamide Gel Electrophoresis (PAGE). 


\subsection{Iodine Test}

Wild sorghum contains $20-30 \%$ amylose, while waxy sorghum mainly contains amylopectin. Amylopectin is reddish-brown after reacting with iodine, in contract, amylose becomes dark blue. They react with iodine presenting different colors because of differences in their degree of polymerization or the relative molecular weight of starch. When the degree of polymerization of amylose is $200-980$ or the relative molecular weight is $32,000-160,000$, the color of the inclusion compound produced by the reaction of starch and iodine is blue. The average degree of polymerization of amylopectin with many branches is $20 \sim 28$, and the inclusion compound is purple or even reddish-brown. Therefore, according to the principle, waxy and wild sorghum can be preliminarily identified by iodine staining method. The waxy seeds are reddish-brown after reacting with iodine solution, and the wild seeds are dark blue. Each cultivar was carried out three times.

\subsection{DNA Isolation and Sequencing}

Two pairs of primers [16] were used to sequence sorghum seeds to determine their genotypes. The first pair primers were Seq-F1 (ACCCAAACCCAGTACAAGGATAAG) and Seq-R1 (ACGGGCTTCTCGTAGCTGCAATC). The primers were to amplify the $5^{\prime}$ region of SbGBSS gene in sorghum. The second pair primers were Seq-F2 (TGGCATC TACAAGGACGCAAAG) and Seq-R2 (TTCTACACGCGATATCAGGGGTC) Which were to amplify the $3^{\prime}$ region of SbGBSS of genomic DNA.

All DNA extraction procedures were conducted using an Ezup Food Genomic DNA Extraction Kit according to the manufacturer's instructions. Briefly, 100-200 mg sorghum powder, $1 \mathrm{~mL}$ GMO buffer and $20 \mu \mathrm{L}$ proteinase $\mathrm{K}$ were added into the centrifuge tube. These were incubated at $65^{\circ} \mathrm{C}$ for $30 \mathrm{~min}$ and centrifuged at $12,000 \mathrm{rpm}$ for $10 \mathrm{~min}$. After that, $400 \mu \mathrm{L}$ chloroform was added to the supernatant, and the mixture was centrifuged at $12,000 \mathrm{rpm}$ for $10 \mathrm{~min}$. The new supernatant was transferred to a new centrifuge tube. The experimenter added GMP buffer into the new centrifuge tube, centrifuged it at 12,000 rpm for $5 \mathrm{~min}$, then discarded the supernatant and retained the sediment. Then, $350 \mu \mathrm{L}$ DRL buffer and $300 \mu \mathrm{L}$ anhydrous ethanol were added to the sediment. All of them were transferred to the adsorption column after the sediment was fully suspended. Next, the adsorption column was centrifuged at 10,000 rpm for $2 \mathrm{~min}$. Following, the solution was poured out in a collection tube. $500 \mu \mathrm{L}$ wash solution was added to the adsorption column, and it was centrifuged at 10,000 rpm for $1 \mathrm{~min}$. The experimenter needed to repeat this operation twice. Then, the solution in the collection tube was poured out again, and the adsorption column was centrifuged at 12,000 rpm for $2 \mathrm{~min}$. Finally, the experimenter took out the adsorption column, put it into a new centrifuge tube, added $30 \mu \mathrm{L}$ of nuclease-free $\mathrm{H}_{2} \mathrm{O}$ or TE buffer, and centrifuged it at 12,000 rpm for $2 \mathrm{~min}$. The quantity and quality of the obtained DNA solution were measured with a microplate reader Synergy H1 (BioTek, Winooski, VT, USA) and stored at $-20{ }^{\circ} \mathrm{C}$ for subsequent experiments.

\subsection{Primer Design and PCR Amplification}

Ten allele-specific forward primers and reverse primers were designed to distinguish between $w x^{c}$ and non- $w x^{c}$. The primers are listed in Table S1.

The PCR reactions were performed in a final volume of $20 \mu \mathrm{L}$ and contained $1 \mu \mathrm{L}$ of DNA template, $1 \mu \mathrm{L}$ of forward primer $(0.2 \mu \mathrm{M}), 1 \mu \mathrm{L}$ of reverse primer $(0.2 \mu \mathrm{M}), 10 \mu \mathrm{L}$ of SanTaq Plus PCR Master Mix, and $8 \mu \mathrm{L}$ of nuclease-free $\mathrm{H}_{2} \mathrm{O}$. The PCR conditions were proceeded as follows: an initial denaturation at $95{ }^{\circ} \mathrm{C}$ for $10 \mathrm{~min}$; followed by 35 cycles of $95^{\circ} \mathrm{C}$ for $10 \mathrm{~s}, 60^{\circ} \mathrm{C}$ for $1 \mathrm{~min}, 72{ }^{\circ} \mathrm{C}$ for $30 \mathrm{~s}$; and a final extension at $72{ }^{\circ} \mathrm{C}$ for $7 \mathrm{~min}$. PCR amplifications were performed in a ProFlexTM $3 \times 32$-well PCR System (Thermo Fisher Scientific, Waltham, MA, USA).

The $5 \mu \mathrm{L}$ of PCR products in $1 \mu \mathrm{L}$ of $1 \times$ gel loading buffer were used for gel electrophoresis. The gel electrophoresis was performed on the prepared gel ( $3 \%$ agarose-TAE sol-gel with $1 \times$ GelRed dye) in $1 \times$ TAE at $150 \mathrm{~V}$ for $30 \mathrm{~min}$. After electrophoresis, the gel was visualized via Gel Doc XR+ system (Bio-Rad, Hercules, CA, USA). 


\section{5. aARMS-PCR Detection}

A qPCR was performed using a qTOWER3G in a 96-well plate (Analytik Jena AG, Shanghai, China). The allele-specific, qPCR reactions were conducted in a final volume of $20 \mu \mathrm{L}$ and that contained $1 \mu \mathrm{L}$ of DNA template, $1 \mu \mathrm{L}$ of forward primer $(0.2 \mu \mathrm{M}), 1 \mu \mathrm{L}$ of reverse primer $(0.2 \mu \mathrm{M}), 10 \mu \mathrm{L}$ of $2 \times$ PerfectStartTM Green qPCR SuperMix, and $8 \mu \mathrm{L}$ of nuclease-free $\mathrm{H}_{2} \mathrm{O}$. The qPCR procedure involved initial activation steps of $50{ }^{\circ} \mathrm{C}$ for $2 \mathrm{~min}$ and $95^{\circ} \mathrm{C}$ for $10 \mathrm{~min}$, then followed by 40 cycles of $95^{\circ} \mathrm{C}$ for $10 \mathrm{~s}, 60^{\circ} \mathrm{C}$ for $1 \mathrm{~min}$ and $72{ }^{\circ} \mathrm{C}$ for $30 \mathrm{~s}$.

\subsection{Standard Curves}

The DNA extracted in step 2.3 was diluted by nuclease-free $\mathrm{H}_{2} \mathrm{O}$ to a concentration of $100 \mathrm{ng} / \mu \mathrm{L}$. It was then diluted in a continuous tenfold gradient to a minimum concentration of $1.0 \mathrm{pg} / \mu \mathrm{L}$. The standard curve of $\mathrm{wx}^{\mathrm{C}}$ was generated by plotting the cycle threshold $\left(\mathrm{C}_{\mathrm{T}}\right)$ values of the qPCR amplifications from different amounts of DNA (100 ng, $10 \mathrm{ng}, 1 \mathrm{ng}$, $0.1 \mathrm{ng}, 0.01 \mathrm{ng}$ and $0.001 \mathrm{ng}$ ). The $\mathrm{C}_{\mathrm{T}}$ value of each dilution corresponded to the log of the DNA concentration. Meanwhile, the gradient diluted $w x^{c}$ DNA templates were subjected to PCR reaction for electrophoresis analysis.

\subsection{Quantitative Detection in Mixed Cereal Grain Samples}

Mixed DNA samples were prepared using various proportions of DNA templates extracted from sorghum $\left(0,1,5,10,20,50\right.$, and $100 \%$ non- $w x^{\mathcal{C}} \mathrm{DNA}$, with the remainder from $\mathrm{wx}^{\mathrm{c}} \mathrm{DNA}$ ). The $\mathrm{qPCR}$ amplification of DNA mixtures was carried out in triplicate.

\section{Results and Discussion}

The prominent feature of aARMS-PCR lies in its ability to quantitatively detect known mutations with high specificity. The principle of aARMS-PCR for discriminating sorghum species via single-nucleotide identification is illustrated in Scheme 1 . The $\mathrm{wx}^{\mathrm{c}}$ and non- $\mathrm{wx}$ allele-specific forward primers and a common reverse primer were designed according to $\mathrm{wx}^{\mathrm{c}} \mathrm{SNP}$ site. When the $3^{\prime}$ end base A of the $\mathrm{wx}^{\mathrm{c}}$ allele-specific primer matched the $\mathrm{w} \mathrm{x}^{\mathrm{c}} \mathrm{SNP}$ base T, the primer started to extend from the $3^{\prime}$ end of the primer to generate the $w x^{C}$ allele-specific products. In contrast, the $3^{\prime}$ end base $A$ of the $w x^{c}$ allele-specific primer did not match the non- $w x^{c}$ SNP base G, the primer extension was terminated. In general, it is not ideal to distinguish alleles by a single base mutation at the $3^{\prime}$ end of the primer. Thus, a mismatched base is added to the second or third at the $3^{\prime}$ end of the primer for enhancing the specificity of primers [5,24]. This additional mismatch destroys the stability of the pairing between the primer and the non-corresponding template and reduces the amplification efficiency of the non-corresponding template [25]. Thus, for the non- $w x^{c}$, when the mismatched base was placed fourth from the $3^{\prime}$ end of wxt F4 (substitution of $C$ for T), aARMS-PCR yielded the highest discrimination ability between $w x^{c}$ and non- $w x^{c}$ genes. For $\mathrm{wx}^{\mathrm{C}}$, while the mismatch (substitution of $\mathrm{A}$ for $\mathrm{C}$ ) was introduced second from the $3^{\prime}$ end of wxc F4, the wxc F4 could specifically identify $w x^{c}$ waxy sorghum (Figures S1 and S2).

\subsection{Method Validation}

In order to investigate the ability of aARMS-PCR for the discrimination between $\mathrm{wx}^{\mathrm{c}}$ waxy sorghum and non- $\mathrm{wx}^{\mathrm{C}}$ sorghum, three sorghum cultivars were firstly sequenced. The sequencing results are shown in Figure $1 \mathrm{~A}$ and Figure $\mathrm{S} 3$ in the supporting information. The results indicated that 'Hongyingzi' was $w x^{c}$, and 'Jinnuoliang No.6' was $w x^{b}$, and the 'Jin 204' was wild.

Then, allele-specific primers were used for qPCR amplification of 'Hongyingzi' and 'Jinnuoliang No.6' to assure the authenticity of 'Hongyingzi' in the waxy sorghum mixture. A total of $400 \mathrm{ng}$ of the DNA extracted from sorghum was used for aARMS-PCR tests. The qPCR amplification results are shown in Figure $1 \mathrm{C}, \mathrm{D} . \mathrm{C}_{\mathrm{T}}$ values of 'Hongyingzi' amplified by wxc F4 and wxt F4 were 22.59 and 27.58 , respectively. The $C_{T}$ of 'Jinnuoliang No.6' amplified by wxt F4 and wxc F4 were 19.95 and 31.95, respectively. The results indicated 
that wxc F4 and wxt F4 allowed to differentiate the 'Hongyingzi' from the 'Jinnuoliang No.6' species.

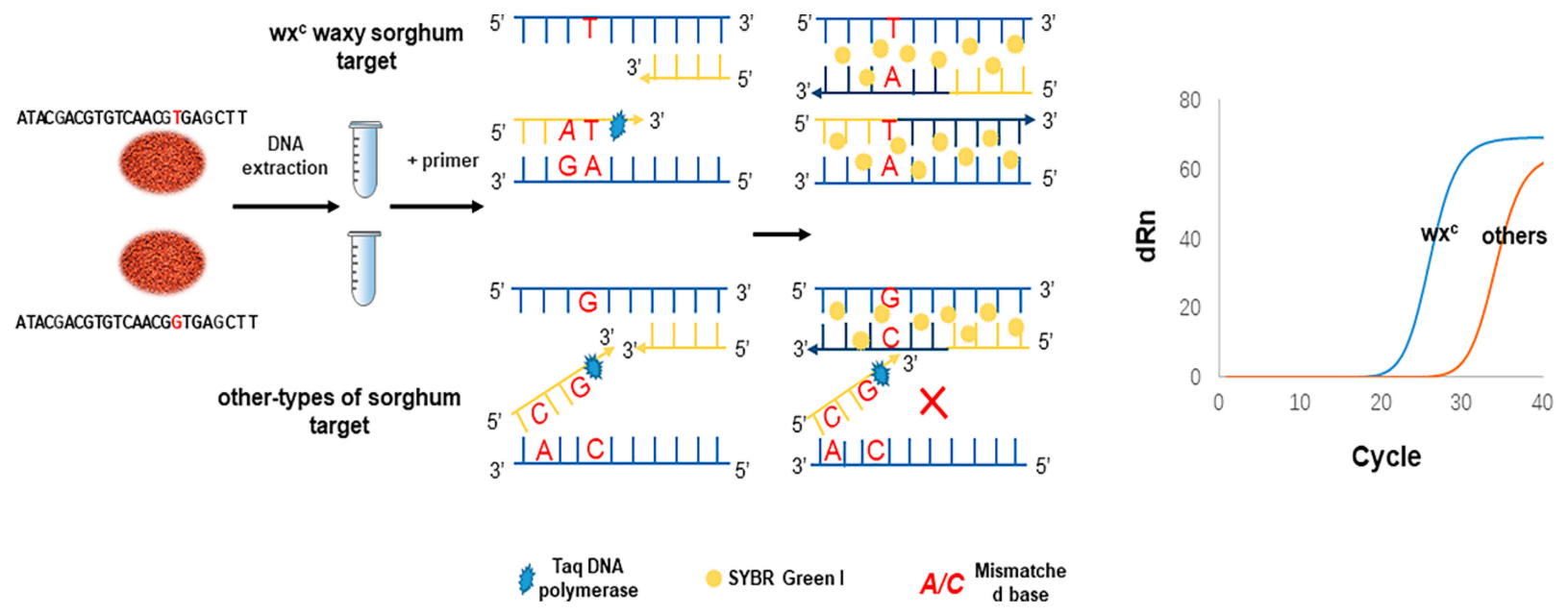

Scheme 1. Schematic illustration of the working principle of aARMS-PCR for distinguishing sorghum species with single-nucleotide resolution.

To verify the accuracy of aARMS-PCR, we performed sorghum iodine staining and PCR experiments. As shown in Figure 1B, 'Hongyingzi' and 'Jinnuoliang No.6' were reddish brown after iodine staining, while 'Jin 204' was dark blue. Therefore, 'Hongyingzi' and 'Jinnuoliang No.6' were waxy sorghum, and 'Jin 204' was wild sorghum. This was consistent with the aARMS-PCR results. The primers wxc F4 and wxt F4, with 'Hongyingzi' and 'Jinnuoliang No.6', were paired for PCR reaction. In order to highlight the specific amplification of 'Hongyingzi' and 'Jinnuoliang No.6' by specific primers, wxc F4 and wxt F4 respectively, the amount of DNA used in PCR was reduced to $50 \mathrm{ng}$, compared with the $400 \mathrm{ng}$ of DNA used in qPCR. The electrophoretic results are shown in Figure 1E. According to the gel imaging results, the 'Jinnuoliang No.6' amplified using wxt F4 and 'Hongyingzi' amplified using wxc F4 yielded bright bands in the corresponding lanes. The location of the bands confirmed the expected sizes of the DNA fragment. In contrast, the 'Jinnuoliang No.6' amplified by wxc F4 and 'Hongyingzi' amplified by wxt F4 were dark in the corresponding lanes. This may be due to the dual effects of the decreased amount of DNA and the lower sensitivity of PCR and electrophoresis than qPCR. Therefore, wxt F4 identified the 'Jinnuoliang No.6', and wxc F4 identified the 'Hongyingzi'. This was consistent with the aARMS-PCR results.

\subsection{Sensitivity of aARMS-PCR}

To determine the sensitivity of aARMS-PCR using PCR and qPCR based on the allelespecific wxc F4, DNA samples were obtained from 'Hongyingzi' grains (100 ng, $10 \mathrm{ng}, 1 \mathrm{ng}$, $0.1 \mathrm{ng}, 0.01 \mathrm{ng}$ and $0.001 \mathrm{ng}$ ). The samples for $\mathrm{QPCR}$ were used to construct the standard curves for quantification of target genes. The detection limit of PCR was down to $1 \mathrm{ng}$ according to the electrophoresis results (Figure 2A). No obvious band was found with an input of DNA templates lower than $1 \mathrm{ng}$. The curve was linear over a range of $100.0 \mathrm{ng}$ to $1.0 \mathrm{pg}$, and the detection limit of wxc F4 was approximately $1.0 \mathrm{pg}$ (Figures 2B and S4). The sensitivity of aARMS-PCR was dramatically enhanced via the replacement of PCR-gel imaging by qPCR. 


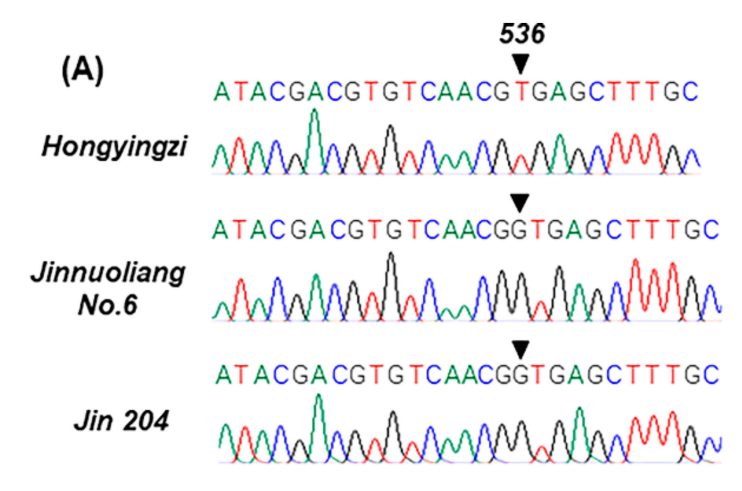

(C) $\infty$

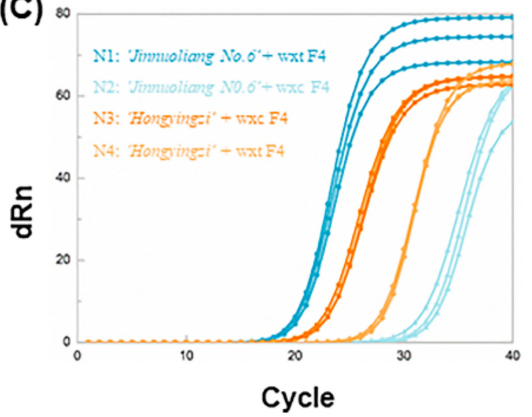

(B)

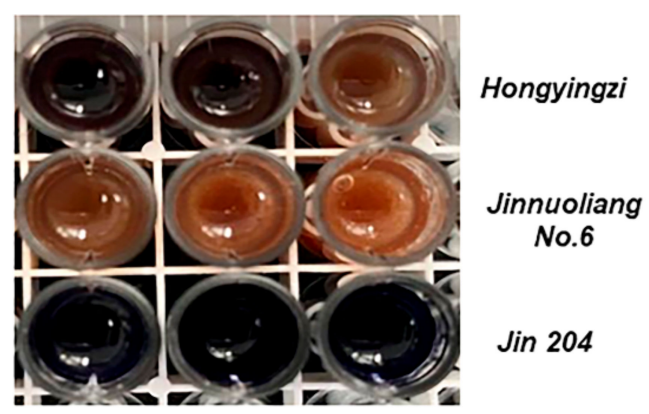

(E)

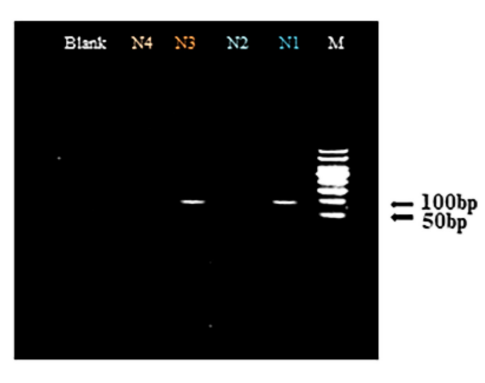

Figure 1. Feasibility of aARMS-PCR method. (A) Sequencing results of 'Hongyingzi', 'Jinnuoliang No.6' and 'Jin 204'. (B) The color results of 'Hongyingzi', 'Jinnuoliang No.6' and 'Jin 204' after dyeing with iodine. (C) Amplification curves obtained by qPCR of 'Hongyingzi' and 'Jinnuoliang No.6' with allele-specific wxt F4 and wxc F4, and the DNA template usage was $400 \mathrm{ng}$. (D) CT values obtained by qPCR of 'Hongyingzi' and 'Jinnuoliang No.6' with allele-specific wxt F4 and wxc F4, and the DNA template usage was 400 ng. (E) Electrophoretic results of 'Hongyingzi' and 'Jinnuoliang No.6' with allele-specific wxt F4 and wxc F4, and the DNA template usage was 50 ng.

\subsection{Quantitation of Adulteration of Sorghum Species Using aARMS-PCR}

The capacity of aARMS-PCR to quantify sorghum adulterations was evaluated using sorghum mixtures. DNA mixtures that contained different proportions of 'Jinnuoliang No.6' $(0 \%, 1 \%, 5 \%, 10 \%, 20 \%, 50 \%$ and $100 \%)$ in mixed 'Jinnuoliang No.6' and 'Hongyingzi' were prepared. An amount of $300 \mathrm{ng}$ of each DNA mixture was then subjected to two separate aARMS-PCR reactions using wxt F4 and wxc F4 along with the R1. Its amplification curve was shown in Figure $S 5 . \Delta C_{T}$ was defined as the difference between $C_{\text {Twxt F4 }}$ and $\mathrm{C}_{\mathrm{Twxc} F}$, to estimate the ratio of products produced by reaction with wxt F4 and wxc F4. The quantification performance using aARMS-PCR was validated by using a series of different concentrations of 'Jinnuoliang No.6' in the mixture. Further, to investigate the detection of aARMS-PCR at low concentrations of 'Jinnuoliang No.6' in mixed grains, a histogram of 'Jinnuoliang No.6' at low concentrations $(0 \%, 1 \%, 5 \%$ and 10\%) was established. The linear regression equation of the $\Delta \mathrm{C}_{\mathrm{T}}$ was calculated as $\mathrm{A}=-0.144 \times \mathrm{B}+3.4855$ $\left(R^{2}=0.9971\right)$ (linear dynamic range, $\left.0-100 \%\right)$, where $A$ and $B$ represented the value of the $\Delta \mathrm{C}_{\mathrm{T}}$ and the content ratio of the 'Jinnuoliang No.6' in the mixture, respectively. $\Delta \mathrm{C}_{\mathrm{T}}$ $\left(\mathrm{C}_{\text {Twxt F4 }}-\mathrm{C}_{\text {Twxc F4 }}\right)$ were greater than 2 at low concentrations (such $1 \%$ and $10 \%$ ), suggesting the aARMS-PCR can endow the ability of quantifying 'Jinnuoliang No.6' in mixed grains. Significant differences as indicated by $\Delta C_{\mathrm{T}}$ between 'Jinnuoliang No.6' with $0 \%$ and $1 \%$ content were observed $(p=0.002<0.01)$, thus reaching a very significant level. We also formed a standard curve and a histogram of 'Jinnuoliang No.6' with different content ratios amplified by wxt F4 (Figure 3B,D). By comparing $\Delta C_{T}$ and $C_{\text {Twxt F4, the data showed that }}$ the $\Delta C_{T}$ had better resolution at low concentration of 'Jinnuoliang No.6' in the mixture. This developed method can detect satisfactorily the authenticity of $\mathrm{wx}^{\mathrm{C}}$ and help to prevent adulteration of non- $\mathrm{w} \mathrm{x}^{\mathrm{C}}$ sorghum. 


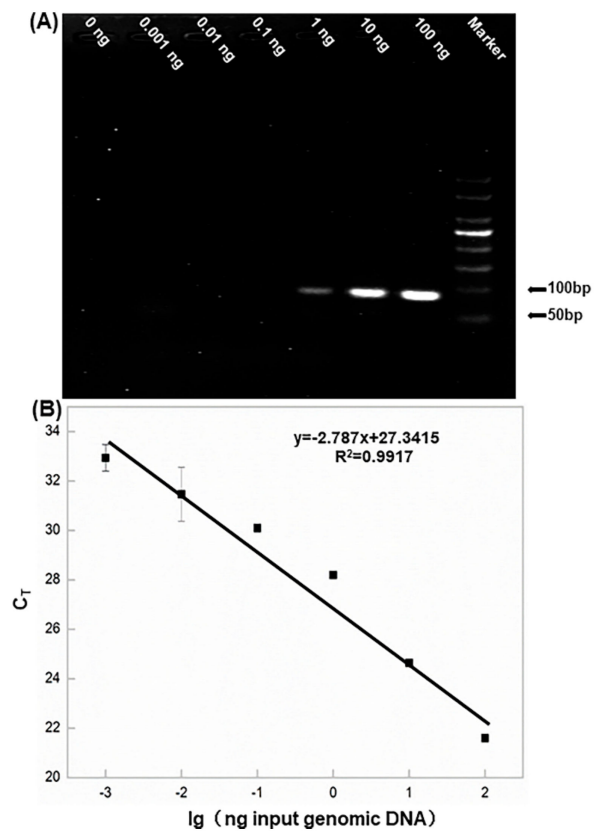

Figure 2. PCR and qPCR with 'Hongyingzi' as standard substance amplified by wxc F4. (A) Electrophoretic analysis of 'Hongyingzi' with ten-fold serially diluted from $100.0 \mathrm{ng}$ to $1.0 \mathrm{pg}$; (B) the relationship between logarithm of the amount of 'Hongyingzi' and the value of CT.
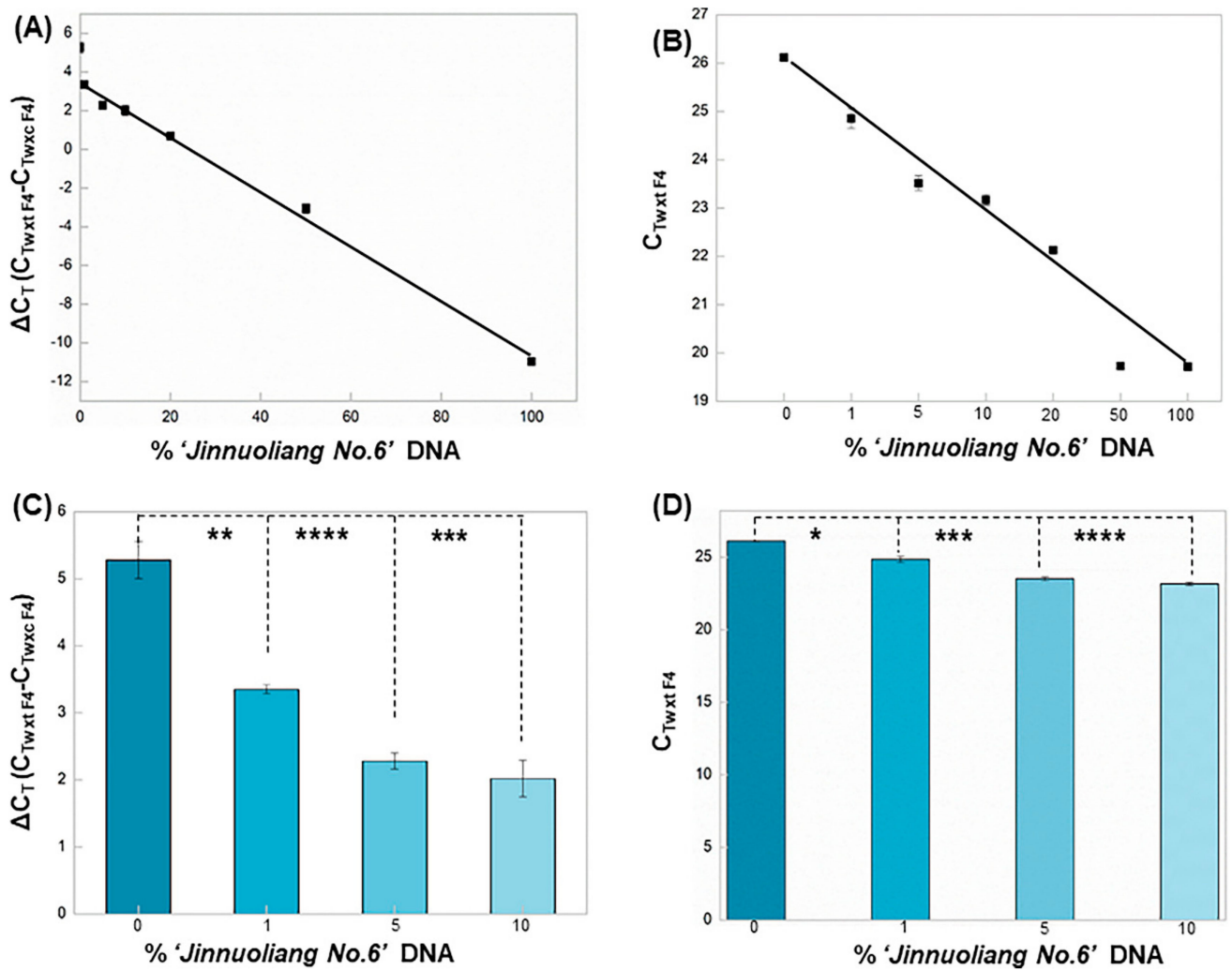

Figure 3. Quantitation of adulteration of aAMRS-PCR. (A) The relationship between 'Jinnuoliang No.6' with different content ratios $(0 \%, 1 \%, 5 \%, 10 \%, 20 \%, 50 \%, 100 \%)$ and $\triangle \mathrm{CT}$ (CTwxt F4-CTwxc F4). (B) The relationship between 'Jinnuoliang No.6 ${ }^{\prime}$ with different content ratios $(0 \%, 1 \%, 5 \%, 10 \%, 20 \%, 50 \%, 100 \%)$ and CTwxt F4. (C) $\Delta$ CT (CTwxt F4-CTwxc F4) of 'Jinnuoliang No.6' with low content ratios (0\%, 1\%, 5\%, 10\%). (D) CTwxt F4 value of 'Jinnuoliang No.6' with low content ratios $(0 \%, 1 \%, 5 \%, 10 \%)$. Statistical significance data were obtained by two-tailed unpaired student's $t$-test: ${ }^{*} p<0.05$, ** $p<0.01,{ }^{* * *} p<0.001,{ }^{* * * *} p<0.0001$. 


\section{Conclusions}

In summary, we introduced an aARMS-PCR method for the discrimination of adulteration in sorghum samples. The assay presents novel features: (1) specific recognition, the assay can identify species with single base differences; (2) high sensitivity: aARMS-PCR can

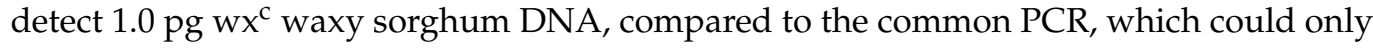
detect $1.0 \mathrm{ng}$ DNA. In addition, aARMS-PCR can detect as low as $1 \%$ non- $w x^{C}$ sorghum in mixtures including $\mathrm{wx}^{\mathrm{C}}$ waxy sorghum; (3) This is a potential universal platform: the successful applications of this assay for determining $w x^{\mathrm{C}}$ waxy sorghum and non- $w x^{\mathrm{C}}$ sorghum indicate its robustness for quantifying samples. Therefore, aARMS-PCR can serve in routine food integrity and authenticity tests.

Supplementary Materials: The following are available online at https:/ /www.mdpi.com/article/10 .3390/foods10092218/s1, Table S1: Oligonucleotide sequences. Figure S1: Primers screening. Several allele-specific forward primers designed for wxc waxy sorghum and non-wxc sorghum were used for qPCR amplification; Figure S2: CT values of qPCR amplification for screening primers that specifically identified wxc waxy sorghum and non-wxc sorghum. The allele-specific forward primers wxc F0, F1, F2, F3 and wxt F0, F1, F2 and F3 designed for wxc waxy sorghum and non-wxc sorghum could not specifically identify wxc waxy sorghum or non-wxc sorghum; Figure S3. Partial DNA sequence information about 'Hongyingzi', 'Jinnuoliang No.6' and 'Jin 204'. 'Hongyingzi' was wxc, and 'Jinnuoliang No.6' was wxb, and the 'Jin 204' was wild; Figure S4. The amplification curves of 'Hongyingzi' DNA samples that were continuously ten-fold diluted from $100.0 \mathrm{ng}$ to $1.0 \mathrm{pg}$; Figure S5. Amplification curves of 'Jinnuoliang No.6' with different content ratios in mixtures.

Author Contributions: Data curation, X.Z.; Formal analysis, X.Z.; Funding acquisition, X.W.; Methodology, M.R.K.; Project administration, A.L.; Resources, W.D.; Software, R.B.; Supervision, S.D.; Validation, M.W. and A.L.; Writing—original draft, X.Z.; Writing—review and editing, R.D. All authors have read and agreed to the published version of the manuscript.

Funding: This work was financially supported by Sichuan-Luzhou strategic cooperation project (No. 2019CDLZ-02), Sichuan technological transformation program (No. 2019ZHCG0073) and the Researchers Supporting Project Number (RSP-2021/138), King Saud University, Riyadh, Saudi Arabia.

Institutional Review Board Statement: Not applicable.

Informed Consent Statement: Not applicable.

Data Availability Statement: Not applicable.

Acknowledgments: We acknowledge Sichuan Langjiu Group Co., Ltd and Sichuan Academy of Agricultural Sciences for kindly providing us with the sorghum samples.

Conflicts of Interest: The authors have declared no conflict of interest.

\section{References}

1. Sattler, S.E.; Singh, J.; Haas, E.J.; Guo, L.; Sarath, G.; Pedersen, J.F. Two distinct waxy alleles impact the granule-bound starch synthase in sorghum. Mol. Breed. 2009, 24, 349-359. [CrossRef]

2. Trantakis, I.A.; Spaniolas, S.; Kalaitzis, P.; Ioannou, P.C.; Tucker, G.A.; Christopoulos, T.K. Dipstick test for DNA-based food authentication. Application to coffee authenticity assessment. J. Agric. Food Chem. 2012, 60, 713-717. [CrossRef]

3. Wang, D.; Bean, S.; Mclaren, J.; Seib, P.; Madl, R.; Tuinstra, M.; Shi, Y.; Lenz, M.; Wu, X.; Zhao, R. Grain sorghum is a viable feedstock for ethanol production. J. Ind. Microbiol. Biotechnol. 2008, 35, 313-320. [CrossRef] [PubMed]

4. Smith, O.S.; Smith, J.S.C.; Bowen, S.L.; Tenborg, R.A.; Wall, S.J. Similarities among a group of elite maize inbreds as measured by pedigree, f1 grain yield, grain yield, heterosis, and rflps. Theor. Appl. Genet. 1990, 80, 833-840. [CrossRef]

5. Liu, J.; Huang, S.; Sun, M.; Liu, S.; Liu, Y.; Wang, W.; Zhang, X.; Wang, H.; Hua, W. An improved allele-specific pcr primer design method for snp marker analysis and its application. Plant Methods 2012, 8, 34. [CrossRef] [PubMed]

6. Sang, Y.; Bean, S.; Seib, P.A.; Pedersen, J.; Shi, Y.-C. Structure and functional properties of sorghum starches differing in amylose content. J. Agric. Food Chem. 2008, 56, 6680-6685. [CrossRef]

7. Murugaiah, C.; Noor, Z.M.; Mastakim, M.; Bilung, L.M.; Selamat, J.; Radu, S. Meat species identification and halal authentication analysis using mitochondrial DNA. Meat Sci. 2009, 83, 57-61. [CrossRef]

8. Hu, Y.; Huang, S.Y.; Hanner, R.; Levin, J.; Lu, X. Study of fish products in metro vancouver using DNA barcoding methods reveals fraudulent labeling. Food Control 2018, 94, 38-47. [CrossRef] 
9. Mezgebe, A.G.; Taylor, J.R.N.; De Kock, H.L. Influence of waxy (high amylopectin) and high protein digestibility traits in sorghum on injera sourdough-type flatbread sensory characteristics. Foods 2020, 9, 1749. [CrossRef] [PubMed]

10. Wong, J.H.; Lau, T.; Cai, N.; Singh, J.; Pedersen, J.F.; Vensel, W.H.; Hurkman, W.J.; Wilson, J.D.; Lemaux, P.G.; Buchanan, B.B. Digestibility of protein and starch from sorghum (sorghum bicolor) is linked to biochemical and structural features of grain endosperm. J. Cereal Sci. 2009, 49, 73-82. [CrossRef]

11. Elhassan, M.S.M.; Emmambux, M.N.; Hays, D.B.; Peterson, G.C.; Taylor, J.R.N. Novel biofortified sorghum lines with combined waxy (high amylopectin) starch and high protein digestibility traits: Effects on endosperm and flour properties. J. Cereal Sci. 2015, 65, 132-139. [CrossRef]

12. Chen, A.; Wei, C.; Chen, G.; Zhao, Y.; Yang, S. Duplex pcr approach for the detection and quantification of donkey, horse and mule in raw and heat-processed meat products. Int. J. Food Sci. Technol. 2015, 50, 834-839. [CrossRef]

13. Aldeguer, M.; Lopez-Andreo, M.; Gabaldon, J.A.; Puyet, A. Detection of mandarin in orange juice by single-nucleotide polymorphism qpcr assay. Food Chem. 2014, 145, 1086-1091. [CrossRef] [PubMed]

14. Skouridou, V.; Tomaso, H.; Rau, J.; Bashammakh, A.S.; El-Shahawi, M.S.; Alyoubi, A.O.; O'sullivan, C.K. Duplex pcr-elona for the detection of pork adulteration in meat products. Food Chem. 2019, 287, 354-362. [CrossRef]

15. Pedersen, J.F.; Bean, S.R.; Graybosch, R.A.; Park, S.H.; Tilley, M. Characterization of waxy grain sorghum lines in relation to granule-bound starch synthase. Euphytica 2005, 144, 151-156. [CrossRef]

16. Lu, Y.; Zhao, G.; Li, Y.; Fan, J.; Ding, G.; Zhao, J.; Ni, X.; Xu, Y.; Wang, W. Identification of two novel waxy alleles and development of their molecular markers in sorghum. Genome 2013, 56, 283-288. [CrossRef] [PubMed]

17. Kim, W.J.; Yang, S.; Choi, G.; Park, I.; Noh, P.; Kim, M.J.; Moon, B.C. Accurate and rapid identification of longan arillus and litchi semen by a multiplex pcr assay. Plants 2020, 17, 948. [CrossRef]

18. Wang, Z.; Wang, Z.; Li, T.; Qiao, L.; Liu, R.; Zhao, Y.; Xu, Z.; Chen, G.; Yang, S.; Chen, A. Real-time pcr based on single-copy housekeeping genes for quantitative detection of goat meat adulteration with pork. Int. J. Food Sci. Technol. 2019, 55, 553-558. [CrossRef]

19. Hill, H.; Lee, L.S.; Henry, R.J. Variation in sorghum starch synthesis genes associated with differences in starch phenotype. Food Chem. 2012, 131, 175-183. [CrossRef]

20. Cho, J.; Jung, T.; Kim, J.; Song, S.; Ko, J.; Woo, K.; Lee, J.; Choe, M.; Oh, I. Development of a waxy gene real-time pcr assay for the quantification of sorghum waxy grain in mixed cereal products. BMC Biotechnol. 2015, 15, 20. [CrossRef]

21. Abi, A.; Safavi, A. Targeted detection of single-nucleotide variations: Progress and promise. ACS Sens. 2019, 4, 792-807. [CrossRef] [PubMed]

22. $\mathrm{Hu}, \mathrm{Y}$; $\mathrm{Lu}, \mathrm{X}$. Rapid pomegranate juice authentication using a simple sample-to-answer hybrid paper/polymer-based lab-on-achip device. ACS Sens. 2020, 5, 2168-2176. [CrossRef] [PubMed]

23. Cheubong, C.; Yoshida, A.; Mizukawa, Y.; Hayakawa, N.; Takai, M.; Morishita, T.; Kitayama, Y.; Sunayama, H.; Takeuchi, T. Molecularly imprinted nanogels capable of porcine serum albumin detection in raw meat extract for halal food control. Anal. Chem. 2020, 92, 6401-6407. [CrossRef] [PubMed]

24. Chen, F.; Zhao, Y.; Fan, C.; Zhao, Y. Mismatch extension of DNA polymerases and high-accuracy single nucleotide polymorphism diagnostics by gold nanoparticle-improved isothermal amplification. Anal. Chem. 2015, 87, 8718-8723. [CrossRef]

25. Petralia, S.; Conoci, S. Pcr technologies for point of care testing: Progress and perspectives. ACS Sens. 2017, 2, 876-891. [CrossRef] 